\title{
Email Marketing between Effectiveness and Inconvenience: A Case of Travel Agencies in Cairo
}

\section{Sameh Ahmed Refaat Abdel Baky Ahmed}

Department of Tourism Studies, Faculty of Tourism \& Hotel Management, Helwan University, Cairo, Egypt

Department of Tourism \& Hospitality Management, College of Tourism and Archaeology, King Saud University, Riyadh, Saudi Arabia

\begin{abstract}
Email marketing emerged as a viable marketing activity in the 1990s with the ascent of the Internet. As web sites and web traffic proliferated, businesses were able to use email to reach growing numbers of potential customers at a very low cost. Specifically hospitality and travel firms use e-mail marketing in maintaining a long-term relationship with customers. With the fact that empirical studies on e-mail newsletters are nil, especially studies focusing on e-mail newsletters in the hospitality and travel industries, this study proceeds with considering literature on email marketing, customer retention and relationship marketing together with information on hospitality and travel firms to provide insights into the effectiveness of using e-mail newsletters. The study depends on an empirical study based on a questionnaire survey of a probability random sample of travel agents' clients in Cairo, to understand their views, the level of their interest and level of influence by email marketing in general and travel agents' email marketing in particular.
\end{abstract}

Keywords: Email Marketing, Travel Marketing, Travel \& Tourism, Customers, (ROI) Return on Investment
Abbreviations:
(CRM) Customer Relationship Management
(ROI) Returns on Investments
(B2B) Business to Business email marketing
(B2C) Business to Customers email marketing

\section{Introduction}

Nowadays email marketing is increasingly recognized as a cost-effective marketing tool in different organizations to market their products or services. Further email marketing provided marketers with communication that permitted relationship building and real-time interaction with customers (Venugopal, et al, 2012). Moreover, permission-based e-mails sent to customers is a form of marketing that is on the increase, email marketing campaigns produce approximately twice the return on investment of the other main forms of online marketing such as Web banners and online directory adverts. Studies of email marketing campaigns, however, are rare (Fiona and Doherty, 2012).

Furthermore, Venugopal, et al, (2012) add that email marketing becomes the Internet's killer application because of the precision with which email can be tailored, targeted and tracked with this low costs and digital processing allows companies to send out huge numbers of emails.

Alikilic, (2008) explains that travel and tourism industry is intangible so as it is more than a product and it depends on images reflected by the mass communication channels as well as the interpersonal relations. Tourism images are built through many channels; governmental authorities, local municipalities, operators, tourism agents, travel consultants, news media, entertainment media. In this regards, Ting, (2012) focuses that email newsletters support building images and customer retention by establishing and maintaining continuous communication and interaction of hospitality and travel firms with customers. So, with email marketing, companies may deliver the right message to the right person, on the right time, and in the channel most preferred by the customer. Tourism and travel professionals should rely on email marketing to acquire new customers 
(potentials) and strengthen relationships with actual ones. Email marketing should be an essential component in tourism and travel industry also (Alikilic, 2008).

\section{Literature Review}

\section{Email Marketing (Overview)}

Rautanen, (2012) defines direct marketing as "communications where data are used systematically to achieve quantifiable marketing objectives, where direct contact is invited or made between a company and its customers and prospective customers."

As email marketing is considered part of direct marketing, it is relevant to show that email marketing is directly marketing a commercial message to a group of people using electronic mail (email) to send ads, solicit sales or donations, request business, or, build loyalty, trust or brand awareness among potential customers (Bawm and Nath, 2014). In its broadest sense, every e-mail sent to a potential or current customer could be considered e-mail marketing (Zahedifard, 2012).

According to the market research firm -The Radicati Group, (2014), in recent years, market research has shown that email marketing is still a more trusted medium for marketers than traditional digital marketing. There are over 2.5 billion email users worldwide and this figure is expected to grow to over 2.8 billion by 2018 and worldwide revenues for the Email Market will grow to over \$23.5billion as against 2018.

Bawm and Nath, (2014) indicate that email marketing has received the attention of numerous marketing researchers, authors, and companies in the past fifteen years. Yeshin, (1998) explains that email marketing is a perfect medium to pick up where other marketing leaves off. Email marketing is still one of the most cost effective ways to contact prospects and customers. It's far cheaper than traditional bulk postage mail and in many cases can have a much larger impact on immediate sales and long-term relationship strength than traditional advertising. Venugopal, et al, (2012) add that when done correctly, email marketing can be an extremely powerful and effective marketing technique. It's a medium that allows a buyer and seller to freely communicate with one another and build a relationship based on value and trust. When done incorrectly, however, email marketing can be destructive, erode brand equity, and turn your happy clients into litigious flamers. Fiona and Doherty (2012) conclude that e-mail marketing is an important medium of marketing communication especially for companies seeking to build and maintain closer relationships with customers.

Stokes, (2012) assures that at its core, email marketing is a tool for customer relationship management (CRM). Used effectively, this extension of permission-based marketing can deliver one of the highest returns on investments (ROI) of any digital marketing activity. It should maximize the retention and value of customers, which should ultimately lead to greater profitability. Also, in the field of integrating email marketing with other marketing channels, whilst email marketing can operate as a standalone marketing campaign, integrating it with other channels, both online and offline will reinforce a brand's message and increase responses.

Zahedifard, (2012) displays the advantages of e-mail Marketing: Most of what you invest, you get, it is very meaningful, measurable, it is easy, it is automatic, it is fast and efficient. On the other hand, disadvantage of email marketing: undelivered e-mail, e-mail response decay, rendering ability, e-mails overload.

Bawm and Nath, (2014) indicate that email marketing software is built and optimized to send bulk emails to subscribers and at the same time make important data available to marketers. Marketers can now easily track and optimize their campaign based on subscribers' activity histories. But, Combined with the fact that most email users find unsolicited e-mail marketing messages as intrusive and many of them have started to take measures to protect themselves from receiving spam, there is little reason for any e-mail marketer to attempt building a relationship with customers without first acquiring their permission. In that context, there are two main strategies for acquiring contact permission from the customer: opt-in and opt-out. The opt-in policy means that the customer must explicitly state he or she gives the permission to be contacted by e-mail. This type of permission can be asked in, for example, the registration process of signing up for a username to an online service. The optout policy requires the customer to actively unsubscribe from the e-mail contacts if he or she does not wish to receive them (Hasouneh and Alqeed, 2010). 
Moreover, studies of email marketing have found the disloyal customers mainly want promotional offers, but loyal customers also appreciate other content, like news, invitations to events, and usage tips (Merisavo, 2006).

Most important best practica tips in email marketing:

- Reaching the inbox. Certified newsletter service providers are whitelisted to ensure that emails reach the inbox without being filtered as spam (Schebesta, 2014).

- Consider frequency and timing. Make sure that emails gain the visibility that they deserve. Target the customer with the right content at the right time. The optimum delivery time will vary depending on the target audience (I Contact, 2012). The rule of thumb: - B2B - workdays (in particular mornings). - B2C- daily, also at the weekend in the mornings or evenings. (Schebesta, 2014);

- Avoiding display errors (Proofread). To guarantee flawless display in all current email programs, you should definitely test your newsletter before dispatching it. Carefully proofread e-mails, paying special attention to figures, discounts and prices (Schebesta, 2014 and SBDC, 2010);

- Securing content display. It is important to make sure that newsletter does not exceed 600px in width; otherwise the recipient will be forced to scroll across laterally to reach all of the content (Schebesta, 2014);

- Make it attractive with relevant and direct content. The design of e-mails should be consistent with the company's website and other marketing materials. Use logo, color highlights, photos and graphics to enhance visual appeal (SBDC, 2010);

- Remember that less is definitely more, email marketing campaigns are best kept short and to the point. Try to keep any scrolling to a minimum (I Contact, 2012);

- Mobile-optimized newsletters. The growth in smartphones and tablets has resulted in a greater percentage of email opens occurring on mobile devices (Schebesta, 2014);

- Get social, to encourage subscribers to socialize email content and to share email marketing messages via their social networks (I Contact, 2012);

- Analyze results. Look for an e-mail marketing service that provides analytic tools. Use analytics to assess the effectiveness of e-mail marketing campaigns (Calculate the ROI) and adjust them for better results (SBDC, 2010).

Rautanen, (2012) summarizes that in general, while searching for alternative marketing and communication channels that have well established ROI (return of investment) none have come even close to email marketing. Simply, it is just so easy and cheap to do that even though results are not totally satisfying it still has better ROI than other channels that can be used.

\section{Email Marketing in Travel \& Tourism}

Ting, (2012) begins that in competing for consumers, gaining new customers has been the priority of hospitality and travel firms. Marketing deals focused on ways of attracting customers. Limited time discounts and service bundles or regularly offering new service features have been ways by which travel firms have attracted new customers. These strategies have resulted in increasing customers of travel agencies, car rentals, hotels, restaurants and tourist destinations. Morgan and Chan, (2011) explain that in an industry as price-driven and customer-driven as travel, companies are feeling an even greater need to strengthen customer relationships and maximize customer retention.

According to the American Society of Travel Agents ASTA (2009), customer retention is the biggest issue for travel firms followed by attraction of new customers. Travel firms need to determine strategies that work in retaining customers. Hospitality and travel firms need to manage customer relationships effectively to ensure continuity. Email marketing and newsletters are old ways of keeping in touch with customers. The idea is to regularly provide customers with update information on the firm including new services, deals or promotions (Ting, 2012). 
In the context of email marketing in travel and tourism, Clowes, (2015) displays that the travel \& tourism industry is one of the most funniest and easiest industries to get some creative and effective email marketing campaigns going in. Experian, (2013) adds that email is a growing source of traffic within the travel industry and although not as prominent as search it provides a very different role as a digital channel. Email presents excellent opportunities to nurture existing customers, to cross-sell other travel products, and to build brand loyalty. One of the keys to unlocking the potential of email marketing in travel is to understand that the seasonality of email works differently from other digital channels. Moreover, this provides a great opportunity for marketers in the travel and tourism industry to keep their brand and services fresh in the minds of their target audience for even longer with some clever email marketing (Clowes, 2015).

Alikilic, (2008) mentions that travel \& tourism practitioners introduce email that is one of the most reliable new medium as a ecommerce driver and customer relationship builder, they also point out that customers still rely on email for their travel and holiday purchasing information, ideas, news and interactive services. Especially "email" as a communication channel is the most effective marketing vehicle for tourism marketers to analyze real-time data at a deep level. Moreover, email produces the highest response rate for lead generation of direct mail methods and email is also the cheapest way of running a travel campaign. In addition, Buhalis and Jun, (2011) show that hoteliers and travel firms have gradually matured and now understand that with long-term, strategic objectives and formats such an email marketing produces higher (ROI) return on investment than "quick fix" solutions.

Alikilic, (2008) points out that travel \& tourism professionals should rely on email marketing to acquire new customers (potentials) and strengthen relationships with actual ones. Email marketing should be an essential component in tourism and travel industry also. With the appropriate email tactics, travel companies may reinforce their customer relationship while converting their offerings to customers.

In the context of email tactics, travel companies should take a connected approach to their email marketing efforts, with the consideration of the increasing number of channels being used by individuals to consume and share information, (vendor, 2010) .

Successful email marketing starts with permission. Permission- based sign-up includes asking consumers for channel preference (Email/SMS), frequency of emails, permission to share newsletters, promotional offers and discounts. Seeking permission helps marketers understand subscriber preferences and plan their campaigns accordingly (Octane.in, 2015).

Following travel email tactics, it is vital that travel companies pay real heed to make sure that their email communications are relevant. It is a competitive sector for email marketing and if your message doesn't hit home then you can be sure somebody else's will (Dot tourism, 2015). Concluding travel email tactics, schedule emails around holidays, seasons or events like: Holiday travel help, Seasonal tips and Industry news (Weber, 2015). Finishing with the case of Booking.com: Email campaigns are a direct and economical way to expose users to products, in the case of booking.com; these emails contain proposed travelling destinations and information about special deals from partner hotels. Both personalized recommendations and deals have an obvious value to the user (Noulas and Einarsen, 2014).

\section{Email Marketing (Facts \& Figures)}

Every year, Hundreds of international specialist companies in marketing and communications allover the world conduct surveys and produce statistics reports on email marketing campaigns, it's analysis and ROI in different fields including travel \& tourism.

\section{Email Marketing Statistics in General}

Schebesta, (2014) shows that $93 \%$ of all ecommerce businesses globally rely on email marketing as a sale and marketing channel. Email marketing is (40) times more effective than Facebook and Twitter marketing combined. According to Trumpia, (2011) and Dally, (2013):

- There were 3.146 billion email accounts worldwide at the end of 2011, growing to 3.6 billion in the end of 2013. $85 \%$ of worldwide internet user's access email. $91 \%$ of consumers check their email at least daily. 
- Investment in email marketing grew from 1.3\$ Billion in 2010 to $2 \$$ Billion in 2014.

- $60 \%$ of Marketers believe that email is a ROI-producing activity.

- 59\% of B2B marketers say that email is the most effective channel in generating revenue. Emails with 1 or 2 words in their subject lines are opened at a higher rate than those with more.

- 50\% of consumer's worldwide trust email message from companies they have signed up to receive.

- Too many emails (69\%) and non-relevant content (56\%) are the top reasons people unsubscribe from emails.

- 27\% of emails were opened on a mobile device during 2011 as against $48 \%$ in 2013.

- Including the word "Exclusive" in email promotional campaigns increases boosts unique open rates by $14 \%$.

- Emails with offers generate $48 \%$ higher revenue than other promotional emails.

$-66 \%$ online consumers have made a purchase as a result of an email.

- Specific types of marketing messages and how consumers like to get them, email is the preferred channel:

- Financial alerts: $52 \%$ prefer email.

- Travel alerts: $43 \%$ prefer email.

- Customer service communication: $76 \%$ prefer email.

- Order confirmations/ receipts: $77 \%$ prefer emails.

- Online ticket delivery: $60 \%$ prefer emails.

- Promotional offers: $66 \%$ prefer emails.

\section{Email Marketing Statistics in Travel and Tourism}

According to Octane, (2015):

- Travel \& tourism industry ranked second place globally at 77 points in using email in.

- Email Marketing being one of the most effective marketing tools for e-travel email audience will grow from 2.42 billion in 2014 to 2.7 billion by 2017. According to Weber, (2015):

- " $63 \%$ of customers who sign up for emails from a travel site are more likely to do business through them for future trips." That's a big percentage of business your site or agency could be diverted from the "big name" travel sites.

- The Epsilon study also shows that $86 \%$ of online consumers sign up for emails from travel sites in search of more special travel offers. $51 \%$ want to know more about vacation packages. Customers and site visitors want information from a Travel Company; and the latter, has the deals and packages they're looking for. Email marketing helps build a relationship between the Travel Company and customers that will keep them coming back for their trip booking needs.

- A permission-based travel email campaign also has a great (ROI) return on investment. In 2011, the ROI for email marketing was $\$ 40.56$ for every $\$ 1$ invested.

\section{Methodology}

The objective of this research is to explore reactions, effects and evaluation of travel agents' clients in relation to email marketing, and explore if the email for travel marketing still has the effectiveness as an attractive marketing tool.

\section{Data Collection}

An online and direct (offline) questionnaire survey is conducted during October to December 2015 using a probability random sample of Egyptian travel agents' clients in Cairo. The total number of targeted sample is (300). (173) of respondents completed the questionnaire achieving a response rate of (57.7\%). Through a screening question it is assured that all respondents have received at least (1) email from a travel agent for travel marketing during the last six months. The respondents consist of tourists and travelers with the assistance of travel agents. 


\section{Measures}

The respondents are asked to note approximately the rate of emails received from travel agents for travel marketing within the last six months. (10) Statements between positive and negative are used to measure the influences of email marketing on travel agents' clients, their views, and reactions to it. Choice is measured by a (5) point scale (Likert Scale) ranging from "Strongly Agree" (1), "Agree" (2), "Neutral" (3), "Disagree" (4) and "Strongly Disagree" (5).

\section{Profile of Sample}

The sample (173 respondents) are with the following characteristics: (gender) $39.5 \%$ female and $60.5 \%$ male.(Age) $13.6 \%$ less than 25 years, $48.7 \%$ from 25 to $40,31.3 \%$ from 41 to 55 , and $6.4 \% 56$ or older. (Education) $18.7 \%$ have completed secondary school, $73.1 \%$ are university graduates, and $8.2 \%$ are post graduates. Also, $79.4 \%$ is living in the great Cairo and $20.6 \%$ in other Egyptian Governorates.

\section{Results \& Discussion}

According to table 1, the respondents are invited to express their reactions to the following statements concerning their experiences with emails for travel marketing. The frequency and percentage shown in the table display the total responses for the choice (1) strongly agree and choice (2) agree for each statement.

Table (1) Frequency, Percentage and T- Test for the Statements of the Questionnaire

\begin{tabular}{|c|c|c|c|}
\hline Statements & $\mathbf{F}$ & $\%$ & Mean T Test \\
\hline $\begin{array}{l}\text { I do not mind receiving emails for marketing in general or } \\
\text { from travel agencies in particular. }\end{array}$ & 108 & $62.4 \%$ & $1.67 * *$ \\
\hline I prefer emails for marketing than postal mail. & 122 & $70.5 \%$ & $2.03 * *$ \\
\hline $\begin{array}{l}\text { I feel that emails for travel marketing are relevant to me } \\
\text { with direct and attractive content. }\end{array}$ & 101 & $58.4 \%$ & $2.09 * *$ \\
\hline $\begin{array}{l}\text { Emails for travel marketing permit me to choose the } \\
\text { frequency of the newsletter. }\end{array}$ & 97 & $56.1 \%$ & $2.41 * *$ \\
\hline $\begin{array}{l}\text { Emails for travel marketing usually encourage me to } \\
\text { browse the site. }\end{array}$ & 120 & $69.4 \%$ & $2.64 * *$ \\
\hline $\begin{array}{c}\text { Majority emails for travel marketing permit me to } \\
\text { unsubscribe at any time. }\end{array}$ & 99 & $57.2 \%$ & $3.02 * *$ \\
\hline Emails for travel marketing are intrusive. & 63 & $36.4 \%$ & $3.43 *$ \\
\hline Emails usually take long time to register. & 72 & $41.6 \%$ & 3.53 \\
\hline $\begin{array}{l}\text { I will not subscribe again to email offers or newsletters for } \\
\text { travel marketing. }\end{array}$ & 57 & $33 \%$ & 4.33 \\
\hline $\begin{array}{l}\text { Overall, I find emails for travel marketing mostly are useful } \\
\text { and it is a positive experience. }\end{array}$ & 109 & $63 \%$ & $2.63 * *$ \\
\hline \multicolumn{4}{|c|}{ Scale 1 to 7 where $(1)$ is strongly agree $\quad$ Base $=173 * * \mathrm{p}<0.01, * \mathrm{p}<0.05$} \\
\hline
\end{tabular}


Table (1) contains the means for the statements and t-test results for significant differences of the statement means. Three sections of statements: First for positive statements, second for negative and third for overall evaluation. The (10) attitudinal statements display high correlation levels between them; (8) of the (10) statements had a correlation coefficient higher than 0.5 and significance at $99 \%$ confidence level with at least one another statement.

The responses to the positive statements are higher than responses to the negative ones. The responses are between $55 \%$ and $70 \%$ to the statements (don't mind receiving marketing emails, preferring email than post mail, feeling of relevance, attractive content of emails and encouraging browsing the travel websites. Moreover, the responses are within $35 \%$ to $40 \%$ to the statements (emails for travel marketing are intrusive, take long time to register and will not subscribe again to email newsletters for travel marketing).

Some additional comments for respondents indicate that: about $31 \%$ of the respondents with positive interactions forward emails to their friends and recommend the site, and $22 \%$ of them have decided to buy travel offers as a result to emails. Also, some respondents say that they would change the format and content of emails to be more relevant. That's why many of respondents with negative reactions to emails indicate that they delete messages indiscriminately because so many are not relevant. Few comments desire that emails for travel marketing include video for attractive visual impression to increase the potential creative impact of email marketing.

Overall, about $63 \%$ of respondents feel the experience with email marketing for travel is positive and only $11 \%$ disagreed strongly, and there is no significant relationship between this positive experience and demographic variables. As a result research hypothesis that "emails for travel marketing still has the effectiveness as an attractive marketing tool" is accepted.

\section{Conclusion}

Actually, email marketing was and still one of the most important tools for marketing in different fields including travel \& tourism industry, because of many advantages such as: cost-effective, building customer relationship, ease of content development, reaching a large customer base and its return on investment (ROI). But, these advantages don't deny the regression of email marketing in the face of other marketing tools and channels.

This paper asks a main question with a main hypothesis, if the email marketing still has the effectiveness on clients or became just a plain annoyance? With a hypothesis that email marketing still has effectiveness as a major marketing tool.

The paper discusses on its focused literature: an overview about email marketing in general, then particularly in travel \& tourism industry and finally displays some important factors and figures about email marketing in general and in travel \& tourism.

To answer the main question of the paper, the method depends on a field study with a questionnaire survey to a probability random sample of travel agents' clients in Cairo to measure their views and reactions to email marketing for travel.

According to the high responses to the positive statements of questionnaire than the negative statements, its statistical analysis, and the overall evaluation of respondents for their previous experiences with email travel marketing, the hypothesis of the paper can be accepted that email marketing still have the effectiveness, but may be it needs to handle some critical issues like (attractive and relevant content, frequency, timing and subscribe) to be more competitive to other latest tools of marketing such social media.

\section{References}

Alikilic, Ö. (2008), “User Generated Content in Tourism Marketing”, Journal of Yasar University, 3(9), pp. 10611080 .

Bawm, Z. and Nath, R. (2014), A Conceptual Model for Effective Email Marketing, 17th Int'l Conf. on Computer and Information Technology, Daffodil International University, Bangladesh, P. 250. 
Buhalis, D. and Jun, S. (2011), E-Tourism, CTR Contemporary Tourism Reviews, published by Good fellow Publishers Limited, Wood Eaton, Oxford: P. 17

Chadwick, F. and Doherty, N. (2012), "Web Advertising: The Role of Email Marketing". Journal of Business Research, 65(6), pp. 843-848. $\quad$ http://dx.doi.org/doi:10.1016/j.jbusres.2011.01.005

Clowes, A. (2015), 3 Top Email Marketing Strategies for Travel and Tourism Campaigns, www.pure360emailmarketing.co.uk, pp.4-11.

Dally, J. (2013), Email Marketing, by the Numbers: 100 Stats That Prove Email Isn't Dead, Content Marketing at Vero, published by Slides Share, available at: http://www.slideshare.net/therealjimmydaly/email-markteing-bythe-numbers-100-stats-that-prove-email-isnt-dead? Related $=2$, [accessed on 10/11/2015].

Dot tourism, (2015), The Complete Guide to Optimizing Your Travel Email Marketing, How to Grow Your Email List, Increase Engagement and Ensure Deliverability, Helping Travel Companies Generate Quality Leads Online. E- Book, available at: www.dottourism.com.

Experian, (2013), Understanding Seasonality in Travel, Maximizing Digital Strategy in Multi-Channel Marketing, Experian Marketing Services, London: www.experian.co.uk/marketingservices, P.7

Fiona, E. and Doherty, F. (2012), "Web Advertising: The Role of Email Marketing", Journal of Business Research, 65 (6), pp. 843-848. http://dx.doi.org/doi:10.1016/j.jbusres.

Hasouneh, A. and Alqeed, M. (2010), "Measuring the Effectiveness of E-mail Direct Marketing in Building Customer Relationship", International Journal of Marketing Studies, 2 (1), P. 55.

I Contact, (2012), The Guide 10 Rules Successful Email Marketing, I Contact LLC. Available on: www.iContact.com, P.P. 5-9.

Merisavo, M. (2006), The Effects of Digital Marketing Communication on Customer Loyalty: An Integrative Model and Research Propositions, Helsinki School of Economics Working Papers W-400, Finland: P.15.

Morgan, J. and Chan, C. (2011), An Introduction to Social CRM for the Travel Industry, A special report from Chess Media Group and Hotel Marketing Strategies, Chess Media Group, P.7. http://www.ChessMediaGroup.com.

Noulas, A. and Einarsen, M. (2014), User Engagement through Topic Modelling in Travel, The Second Workshop on User Engagement Optimization, New York City, USA: P. 4

Octane.in, (2015), E-Travel Marketing India. Path to Purchase 2015, Octane Marketing Pvt. Ltd. India: pp. 14-20.

SBDC Service Centers, (2010), 10 Tips for Successful Email Marketing, Los Angles Regional Networks. P.1.

Schebesta, S. (2014), The 10 Best Practice Tips for Successful Email Marketing in E Commerce Email Marketing, White Paper, Newsletters 2Go, pp. 8-9-12-13.

Available on: www.newsletter2go.com/whitepaper

Stokes, R. (2012), E Marketing: The Essential Guide to Digital Marketing, $4^{\text {th }}$ Edition, Quirk, pp. 170- 186.

Radicati Group Inc., (2014), Email Market, 2014-2018, Available at: http://www.radicati.com/?p=12482. [Accessed on 06 November, 2015].

Rautanen, M. (2012), Email Marketing in Business-To-Business Relationship, Master's Thesis, University of Technology, Helsinki: P. 17.

Ting, Y. (2012), "E-Newsletter as a Marketing Tool for Hospitality and Travel Firms to Retain Customers", African Journal of Business Management, 6 (12), PP.4551-4558, DOI: 10.5897/AJBM11.2620, ISSN 1993-8233 @2012 Academic Journals. 
Trumpia, (2011), Email Marketing by the Numbers, published by Slide Share, available at: http://www.slideshare.net/G3Com/infographic-11-13?related=3, accessed on [10/11/2015], 2011.

Vendor, (2010), Connected Marketing for Travel Providers Imperative Email Marketing Tactics to Drive Profitable Revenue Contribution, Vendor Research, The Relevancy Group LLC, P.5.

Venugopal, K. Das, S. and Murthy, V. (2012), “Email Marketing: A Paradigm Shift to Marketing”, International Journal of Advanced Research in Management and Social Sciences IJARMSS, ISSN: 2278-6236, 1(1), P. 101.

Weber, A. (2015), Email Marketing for Travel Agents \& Sites, A Weber Communications, Connections that last are built in the inbox. Available at: http://www.aweber.com/, P. 14.

Yeshin, T. (1998), Integrated Marketing Communications: The Holistic Approach, Butterworth-Heinemann, Oxford, U.K.

Zahedifard, E. (2012), "E-mail Marketing: Advantages, Disadvantages and Improving Techniques", International Journal of E-Education, E-Business, E-Management and E-Learning, 2 (3), P. 232. 


\section{التسويق عبر البريد الإكترونى ما بين الفعالية و الإزعاج \\ دراسة حالة على شركات العياحة بالقاهرة \\ سامح أحمد رفعت عبد الباقى أحمد}

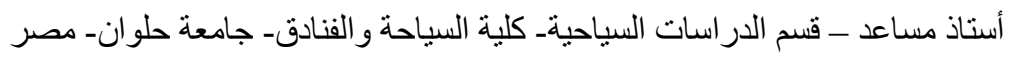

أستاذ مشارك، قسم الإدارة السياحية و الفندقية ـ كلية السياحة والآثار - جامعة الملك سعودــ المملكة العربية السعودية

ملخص البحث

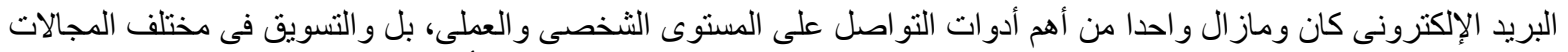

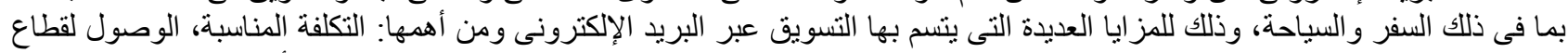

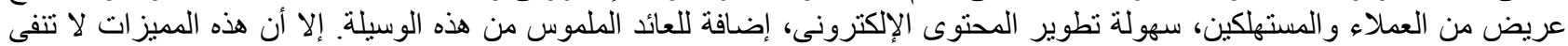

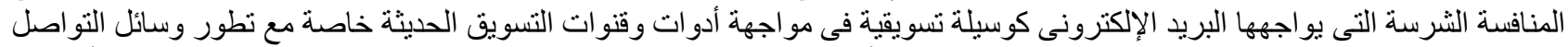

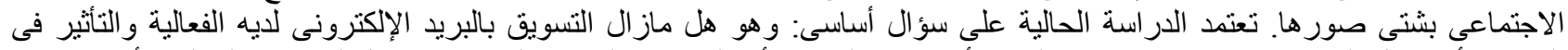

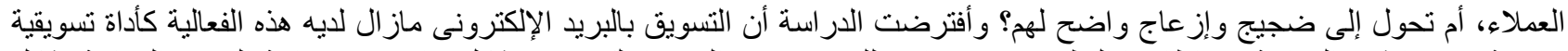

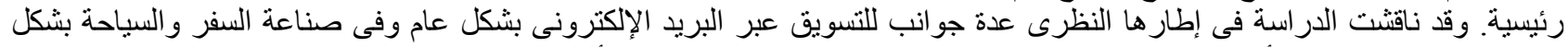

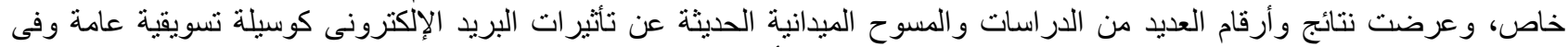

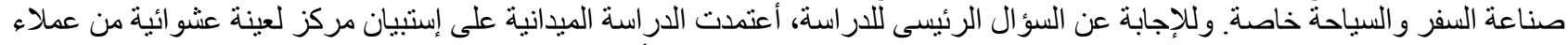

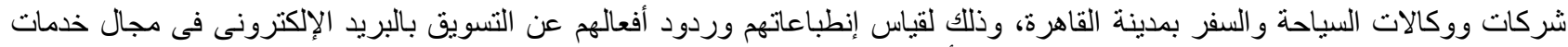

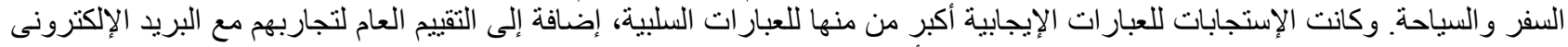

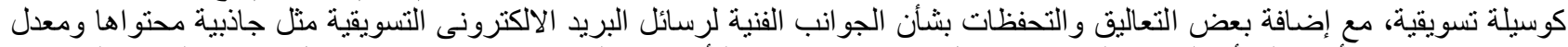

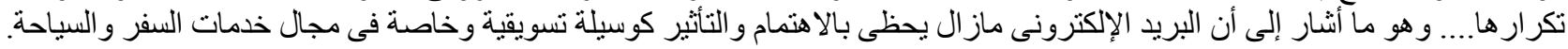
الكلمات الدالة: التسويق بالبريد الإلكترونى، تسويق السفر، السياحة و السفر ، العملاء، العائد على الإستثمار. 